\title{
4.0
}

\section{Introduction and Rationale}

Narratives of crime often bring to light taboos, stereotypes and schemata that relate to gender and sexuality, which is why engaging with such narratives can allow us to question gendered expectations suggested to us as readers. Kate Watson looks at a narrative that deconstructs genre as well as gender-related 'rules', McDermid's The Mermaids Singing, all while employing useful metaphors with which the novel can be read. Charlotte Beyer considers feminist crime writers' recent memoirs and journalism, exploring political and sociocultural elements embedded in them, and arguing that such writers identify their writing as 'deviant' itself, while offering positions that are themselves 'marginalised'. Finally, Mandy Koolen also examines gender and touches on images of femininity and sexuality through challenging heteronormativity. She explores sexological beliefs about lesbianism depicted through film, and argues that Jenkin's filmic Wuornos in Monster reinforces, among others, an association between lesbianism, deviance and violent criminality. She recommends that the character is instead read in all its contradictions and roundness, very much non-simplistically and non-stereotypically. 